\title{
Vulnerability genes or plasticity genes?
}

\author{
J Belsky ${ }^{1}$, C Jonassaint ${ }^{2}$, M Pluess ${ }^{1}$, M Stanton ${ }^{2}$, B Brummett ${ }^{3}$ and R Williams ${ }^{3}$ \\ ${ }^{1}$ Institute for the Study of Children, Families and Social Issues, Birkbeck University of London, London, UK; ${ }^{2}$ Department \\ of Psychology, Duke University, Durham, NC, USA and ${ }^{3}$ Department of Psychiatry, Duke University Medical Center, Durham, \\ NC, USA
}

\begin{abstract}
The classic diathesis-stress framework, which views some individuals as particularly vulnerable to adversity, informs virtually all psychiatric research on behavior-gene-environment $(G \times E)$ interaction. An alternative framework of 'differential susceptibility' is proposed, one which regards those most susceptible to adversity because of their genetic make up as simultaneously most likely to benefit from supportive or enriching experiences-or even just the absence of adversity. Recent $G \times E$ findings consistent with this perspective and involving monoamine oxidase-A, 5-HTTLPR (5-hydroxytryptamine-linked polymorphic region polymorphism) and dopamine receptor D4 (DRD4) are reviewed for illustrative purposes. Results considered suggest that putative 'vulnerability genes' or 'risk alleles' might, at times, be more appropriately conceptualized as 'plasticity genes', because they seem to make individuals more susceptible to environmental influences-for better and for worse.

Molecular Psychiatry (2009) 14, 746-754; doi:10.1038/mp.2009.44; published online 19 May 2009
\end{abstract}

Keywords: genetics; environment $(G \times E)$; parenting; life events

\section{Introduction}

Central to the field of psychiatric genetics is the search for 'vulnerability genes'. ${ }^{1}$ Particularly important in this search is uncovering the mechanisms whereby such genes influence disease risk, and determining whether they are directly associated with more general psychological and behavioral disturbance (that is, act through 'main effects') or whether they are principally related to dysfunction only under specific environmental conditions or in response to particular developmental experiences (that is, act through 'gene- $\times$-environment $(\mathrm{G} \times \mathrm{E})$ interaction'). Findings of studies linking candidate vulnerability genes (or 'risk alleles') directly to specific psychopathological conditions have proven notoriously difficult to replicate. ${ }^{1}$

Failure to replicate direct effects of candidate vulnerability genes on specific psychopathological conditions suggests that genes may not influence behavior directly, leading many investigators to examine how genes may moderate effects of the environment on human $\mathrm{G} \times \mathrm{E}$ interaction. One wellstudied $\mathrm{G} \times \mathrm{E}$ interaction involves monoamine oxidase-A (MAOA), contextual adversity and antisocial behavior. The interaction of a functional MAOA gene polymorphism (MAOA-uVNTR) and childhood adversity, first detected by Caspi et al. ${ }^{2}$ in their research

Correspondence: Professor J Belsky, Institute for the Study of Children, Families and Social Issues, Birkbeck University of London, 7 Bedford Square, London WC1B 3RA, UK.

E-mail: j.belsky@bbk.ac.uk

Received 15 January 2009; revised 10 March 2009; accepted 13 April 2009; published online 19 May 2009 on child maltreatment, has now been replicated enough times that meta-analysis reveals it to be reliable ${ }^{3}$-despite claims by some to the contrary. ${ }^{4}$ Thus, there is growing evidence that individuals possessing the low-MAOA-activity allele are predisposed to become antisocial when they experience a variety of adverse experiences, most notably maltreatment in childhood.

It is not just in the case of the MAOA gene that the notion of genetic vulnerability takes center stage in research on $\mathrm{G} \times \mathrm{E}$ interactions. Consider the evidence showing that the ' $s$ ' allele of the 5-hydroxytryptamine-linked polymorphic region polymorphism (5-HTTLPR) is associated with increased depression in a high-stress context, with the ' $\mathrm{l}$ ' allele functioning protectively. ${ }^{5}$ Several studies have replicated this finding, providing further support for the conclusion that 5-HTTLPR increases vulnerability to depression in the context of environmental stress. ${ }^{6}$

The fundamental premise of this essay, however, is that viewing relations among genes, behavior and the environment from the perspective of the classic diathesis-stress model of psychopathology, as so much psychiatric genetic research on $\mathrm{G} \times \mathrm{E}$ interaction does, may distort these relations and thereby undermine, rather than advance, the understanding of how genes and environment collectively operate to shape behavior and development, including risk of mental illness. Central to the diathesis-stress model is the postulate that some individuals are at heightened risk-because of their genetic make up-of succumbing to psychological disturbance when they encounter adversity, whereas others, lacking the genetic vulnerability, are not so affected even when 
exposed to the very same adversity. Thus, whereas an individual with a particular genetic vulnerability will be prone to develop a genetically specific disorder if he or she experiences what could be some particular or any of a variety of environmental stressors (for example, child abuse, negative life events, death of parent), the same environmental exposure will not engender psychopathology in an individual possessing a different version of the candidate gene in question. ${ }^{7}$

An alternative to the diathesis-stress framework at the heart of genetic vulnerability thinking is the one which presupposes that it is not so much that individuals vary only in their susceptibility to adversity vis-à-vis psychopathology, but rather that these putatively 'vulnerable' individuals are actually more susceptible and, thus, responsive to both positive and negative environmental conditions, that is, in a 'for better and for worse' manner. This differential-susceptibility perspective does not just contend, as many have, that genes are neither inherently good or bad, or even that their developmental and behavioral effects depend on personenvironment fit, ${ }^{8,9}$ but rather-and distinctively-that individuals vary in their plasticity or susceptibility to environmental influences. Thus, the very genes that seem-in so much psychiatric genetic research-to make individuals disproportionately vulnerable to adversity vis-à-vis psychopathology may, simultaneously, confer on them an advantage when it comes to benefiting from exposure to environmental support or enrichment (for example, nurturance), including just the absence of adversity. Were this the case, it would seem more appropriate to speak of 'plasticity genes' rather than 'vulnerability genes' and of highly plastic or malleable individuals rather than the socalled vulnerable ones. Boyce and Ellis, ${ }^{10}$ although not directly concerned with $\mathrm{G} \times \mathrm{E}$ effects, which is the focus of this paper, also have argued that individuals vary in their susceptibility to environmental influences, what they refer to as 'biological sensitivity to context.' However, there is no presumption in their work that such malleability is a function of genotype, as they intriguingly entertain the prospect that experience can shape plasticity.

Ultimately, the purpose of this paper is not so much to challenge the view that diathesis-stress phenomena exist or that processes related to them operate. That seems indisputable. However, it is to contendand illustrate empirically-that in many cases, wherein this may seem to be so, something different may be occurring, yet go virtually unnoticed as a result of expectations derived from the prevailing conceptual perspective, which guides both inquiry and interpretation of findings. Indeed, a central claim of this paper is that the disproportionate attention paid to the negative effects of contextual adversity, broadly defined and varied in its operationalization, on the problematic functioning and on disturbances in development and mental health, may actually lead scholars to mischaracterize environmental influences, as well as human development processes and phe- nomena. And this is because, as stipulated by the differential-susceptibility hypothesis, ${ }^{11-14}$ 'the very same individuals who may be most adversely affected by many kinds of stressors, may simultaneously reap the most benefit from environmental support and enrichment (including the absence of adversity)'.

In the primary body of this paper, we provide extensive but still illustrative $\mathrm{G} \times \mathrm{E}$ evidence to this effect, most of it very recent and much of which has gone unnoticed, even at times by the investigators generating it. What follows should not be regarded as an exhaustive review of the literature; however, nor should it be seen to imply, much less demonstrate, that evidence of differential susceptibility outweighs evidence of diathesis-stress, either in the literature as a whole or even in each and every study cited for illustrative purposes. To make the case, as we exclusively seek to, that differential susceptibility seems operative in human development and functioning, but that individual differences in plasticity have been largely overlooked-in favor of prevailing views that some individuals are simply more vulnerable to adversity than others-it is our contention that an admittedly selective compilation of illustrative $\mathrm{G} \times \mathrm{E}$ findings is exactly what is appropriate at the present time. This would seem especially so in light of the fact that almost all the available human $\mathrm{G} \times \mathrm{E}$ research focuses on both a restricted range of environments, typically emphasizing the negative end of the spectrum and failing to measure at all the positive (except for the absence of adversity), and a restricted range of psychological and behavioral outcomes, also typically emphasizing the negative, thereby failing to assess competent functioning (except for the absence of dysfunction). As a result of these design characteristics of so many $\mathrm{G} \times \mathrm{E}$ investigations, it remains unknown whether extensive evidence consistent with a diathesis-stress model and seemingly inconsistent with a differential-susceptibility framework is an accurate reflection of $\mathrm{G} \times \mathrm{E}$ processes or an artefact of study designs. Quite conceivably, simply treating the absence of adversity as the 'good' end of the environmental-exposure continuum and/or absence of a disorder as the 'good' end of the psychological functioning continuum may lead to the under-detection of differential-susceptibility findings and an over representation of vulnerability ones. It is for these reasons that it is considered appropriate at the present time to provide illustrative evidence of apparent differential-susceptibility effects rather than undertake a formal meta-analysis of $\mathrm{G} \times \mathrm{E}$ findings in hopes of determining which model fits the data better.

\section{Illustrative evidence: MAOA, 5-HTTLPR, dopamine receptor D4 (DRD4)}

Belsky et $a l .{ }^{13}$ recently delineated a series of empirical requirements, or steps, for convincingly establishing evidence of differential susceptibility to environmental influence, that is, individual differences in 
plasticity. The first concerns the application of conventional statistical criteria for evaluating genuine moderation of a putative environmental influence by an organismic plasticity or susceptibility factor, ${ }^{15}$ including genotype, with some emphasis on excluding interactions with regression lines that do not cross (sometimes referred to as removable interactions). The next steps distinguish differential susceptibility from person-environment correlations, including Gene-Environment ones, which may reflect evocative effects of person characteristics on environmental experiences and from diathesis-stress models. If the (genetic) susceptibility factor and the (problematic) outcome are related, diathesis-stress is suggested. The specificity of the differential-susceptibility effect is demonstrated if the model is not replicated when other (genetic) susceptibility factors (that is, moderators) and outcomes are used. ${ }^{16,17}$ Differential susceptibility is thus demonstrated when the moderation reflects a crossover interaction that covers both the positive and the negative aspects of the environment, with the positive typically (and unfortunately) represented by the mere absence of adversity. The slope for the susceptible subgroup should be significantly different from zero and at the same time significantly steeper than the slope for the non-(or less-) susceptible subgroup.

In the remainder of this section, we present illustrative $\mathrm{G} \times \mathrm{E}$ evidence of differential susceptibility to environmental influence that are consistent with the view that individuals differ in their plasticity, with some being more affected than others by experiential influences in a for-better-and-forworse manner. Perhaps, because so much of the work to be cited is new-and often conducted with a diathesis-stress frame of reference in mind-it is actually rare for investigations to address all or even most of the statistical criteria highlighted by Belsky et $a l .{ }^{13}$ for providing convincing evidence of differential susceptibility to environmental influence. Indeed, even when investigators detect statistical interactions of a crossover nature, as is the case in all the researches to be cited, different strategies of following up such interactions are adopted to illuminate their nature. Whereas some investigations adopt a grouping approach for dealing with the interacting predictor variables, plotting or tabling sub-group means, others calculate and contrast slopes reflecting the differential predictive relation between the continuously measured environmental predictor and outcome for groups that differ on the moderating susceptibility factor. Only rarely is it reported whether such slopes differ significantly from each other, as would be preferable when the moderator does not have a natural break point, but is a continuous dimension (but as is not be required when the moderator is naturally categorical with only two categories). Perhaps analogously, it is not always reported when the subclass means are plotted and exactly which mean differs significantly from which others.

In the service of illustrating what seems to be individual differences in plasticity, and thus, differ- ential susceptibility in existing $\mathrm{G} \times \mathrm{E}$ research, we adopt a liberal standard of evidence once a significant crossover interaction has been detected when it comes to regarding the results as evidence of differential susceptibility to environmental influences. Specifically, and with regard to subgroup means, if one subgroup shows both the highest and the lowest mean of all susceptibility-factor-defined subgroups (for example, short vs long 5-HTTLPR allele) on an outcome with regard to the environmental effect in question, this is interpreted as in line with the for-better-and-for-worse differential-susceptibility patterning of results. Similarly, but with regard to slopes, whenever they indicate that one subgroup defined on the basis of the susceptibility factor in question would score highest and lowest given the environmental influence under investigation (that is, steepest slope), this too is interpreted as evidence of differential susceptibility. All the findings to be presented meet these criteria, with some pertaining to MAOA, some to 5-HTTPLR and some to DRD4.

\section{Monoamine oxidase- $A$}

Often unnoticed in Caspi et al.'s ${ }^{2}$ groundbreaking $\mathrm{G} \times \mathrm{E}$ research showing that males with the less active version of the MAOA gene proved most antisocial in young adulthood when they experienced maltreatment in childhood, is that individuals with the same MAOA allele scored lowest in anti-social behavior when not exposed to child maltreatment, even if not by much. A re-interpretation of this study's results in terms of plasticity and differential susceptibility rather than vulnerability and diathesis stress would seem viable given results of a significant number of efforts to replicate the findings. For example, Kim-Cohen et al. ${ }^{3}$ studied 975 boys to determine whether the MAOA polymorphism moderated effects of mother-reported physical abuse in early childhood on later mental health problems. At age 7 years, boys with the low-MAOA-activity variant were rated by mothers and teachers as having more mental health problems-and specifically attention-deficit hyperactivity disorder (ADHD) symptoms-if they had been victims of abuse, but fewer problems if they had not, compared with boys with the high-MAOA-activity genotype. In another longitudinal study, this one of 514 adolescent twin boys aged 8-17 years, Foley et $a{ }^{18}{ }^{18}$ found that childhood adversity-based on parent and child report-predicted a 3-month history of conduct disorder (DSM-III, Diagnostic and Statistical Manual (of mental disorders)) differently for children with and without the low-activity-MAOA allele. Once again, boys with the low-MAOA-activity allele were more likely to be diagnosed with conduct disorder if exposed to higher levels of childhood adversity and less likely if exposed to lower levels of adversity, compared with boys with the high-MAOAactivity allele. Similar results emerged in Nilsson et al.'s ${ }^{19}$ cross-sectional investigation of 81 adolescent boys when the predictor was psychosocial risk, operationalized in terms of maltreatment experience 
and living arrangement. Only boys with the lowMAOA-activity allele were affected by such risk, such that those with a history of adversity engaged in more criminal behavior (composite of vandalism, violence, stealing) and those lacking this history engaged in less.

Three additional studies extend the Caspi et $a .^{2}$ findings: one was a prospective investigation of 631 male and female, and white and black victims of (court-substantiated) child abuse and neglect, along with a comparison group matched on age, sex, race/ ethnicity and social class background; ${ }^{20}$ the second one a retrospective study of 235 adult psychiatric outpatients and healthy controls who reported on trauma experienced in childhood and physical aggression in adulthood; ${ }^{21}$ and the last one a crosssectional retrospective study with an American Indian sample of 291 adult women, 50\% of whom had a history of childhood sexual abuse. ${ }^{22}$ White (but not black) males and females with the low-MAOAactivity allele in the longitudinal study manifested the most lifetime violent and antisocial behavior during adolescence, as well as around age 40, if they had been maltreated, but the least (at both times of measurement) if they had not been victims of abuse. In the second study, men (only) with the low-MAOAactivity variant reported more physical aggression if they experienced one or more (retrospectively reported) objective traumatic events while growing up (for example, death of mother, severe physical handicap of sibling) and less physical aggression if there was no history of trauma, compared with highMAOA-activity men (for whom trauma proved unrelated to aggression). In the third study, women homozygous for the low-MAOA-activity variant had the highest count of antisocial personality disorder symptoms when reporting childhood sexual abuse and the lowest count when having no history of sexual abuse, compared with women homozygous for the high-activity allele. In all inquiries except for the one by Kim Cohen et al., ${ }^{3}$ the MAOA polymorphism proved unrelated to the environmental predictor and to the outcome investigated, consistent with a differential-susceptibility interpretation.

\section{The 5-hydroxytryptamine-linked polymorphic region} polymorphism

Again breaking the empirical ground in $\mathrm{G} \times \mathrm{E}$ research, Caspi et al. ${ }^{5}$ were the first to show that the 5-HTTLPR moderates effects of stressful life events during early adulthood on depressive symptoms as well as on probability of suicide ideation/attempts, and of major depression episode at age 26 years. Individuals with two 's' alleles proved most adversely affected, whereas effects on 1/l genotypes were weaker or entirely absent. Of special significance, given our focus on differential susceptibility, is that carriers of the s/s genotype scored best on the outcomes just mentioned when stressful life events were absent, though this was just as true among low-MAOA activity individuals in Caspi et al., ${ }^{2}$ although not by very much.
Several research groups have attempted to replicate Caspi et al.'s ${ }^{5}$ findings of increased vulnerability to depression in response to stressful life events for individuals with one or more copies of the 's' allele, with most succeeding (see below), even if not all (for example, Surtees et al. ${ }^{23}$ ). Going unnoticed in most, even if not all, of this work to be summarized below, however, is the fact that those carrying short alleles (s/ s, s/l) did not just function most poorly when exposed to many stressors, but best-showing least problems-when encountering few or none of the stressors. Consider, for example, Taylor et al.'s ${ }^{24}$ findings (appreciated by the investigators) showing that young adults homozygous for short alleles (s/s) manifested greater depressive symptomatology than individuals with other allelic variants when exposed to early adversity (that is, problematic childrearing history) as well as many recent negative life events, consistent with a diathesis-stress framework, yet the fewest symptoms when they experienced a supportive early environment or recent positive experiences, that is-and importantly-not just the absence of adversity. A similar for-better-and-for-worse pattern of environmental effects emerged in still other investigations of stressful life events and depression, including one targeting depressed patients, healthy controls and experiences during the 6 months before study enrollment, ${ }^{25}$ and another of a sizeable community sample $(n=567)$ and life events up to 2 years before the assessment of depression. ${ }^{26}$

The same for-better-and-for-worse pattern of results are evident-and noted-in Brummett et al.'s ${ }^{27}$ investigation of more than 200 adults (mean age 58 years) who differed in whether or not they served as caregiver of a relative with Alzheimer's disease (see Figure 1) and in Eley et al.'s ${ }^{28}$ research on adolescent girls who were and were not exposed to risky family environments. Indeed, careful consideration of Figure 1 in Eley et al.'s ${ }^{28}$ report reveals a beneficial

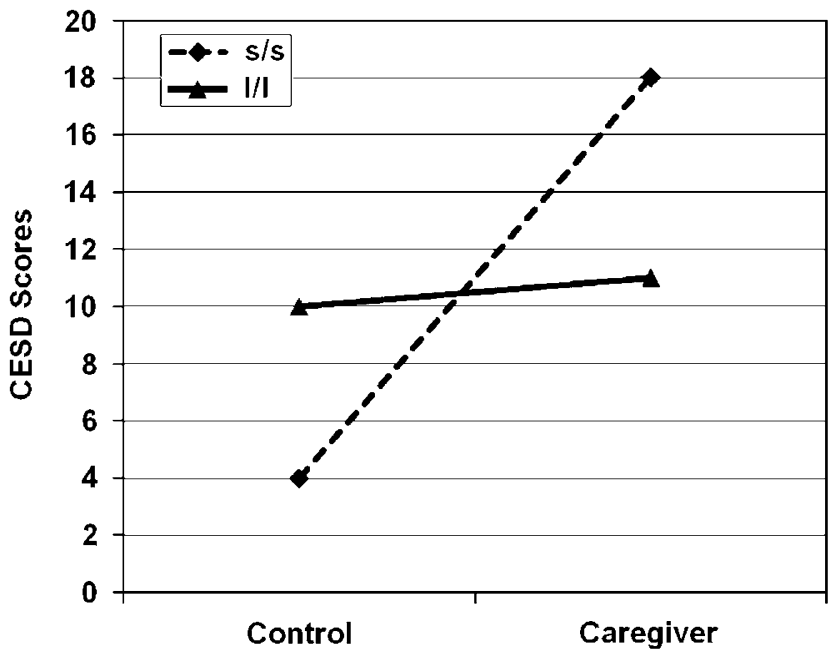

Figure 1 Center for Epidemiological Studies-Depression (CESD) scores for female caregivers and non-caregiver controls by 5 -HTTLPR genotype (Brummett et al. ${ }^{27}$ ). 
effect of the s/s genotype in low-stress environments, with females homozygous for short alleles being $25 \%$ less likely to be in the high depression group than $1 / 1$ participants. This positive effect is actually greater than the negative one described by the authors in the case of the s/s genotype in a high stress environment (that is, 20\% more likely to be in high depression group than 1/1). Re-graphing Eley et al.'s ${ }^{28}$ Figure 1 using the format adopted originally by Caspi et al. ${ }^{5}$ brings this fact to the fore (see Figure 2 below). Comparison of the two figures highlights graphically the point being made repeatedly: the s/s genotype is associated with elevated depressive symptoms or risk among women in high-stress environments, yet among those in low-stress environments the s/s genotype is associated with reduced depressive symptom levels or risk relative to women with the l/l genotype. Wilhelm et al.'s ${ }^{29}$ longitudinal data document the same pattern in an investigation of probability of life-time major depression and exposure to adverse events across a 5-year study period.

The effect of 5-HTTLPR in moderating environmental influences in a manner consistent with differential susceptibility is not restricted to depression and its symptoms, but also-and perhaps unsurprisingly - to anxiety and ADHD. Gunthert et $a .^{30}$ documented the former result in a longitudinal study of 350 college students. At study entry and a year later, participants reported anxiety and negative events daily for 30 days. Genotyping distinguished three alleles, but the $\mathrm{L}_{\mathrm{G}}$ allele was grouped with ' $\mathrm{s}$ ' alleles owing to its functional equivalence vis-à-vis promoter activity. Individuals judged homozygous for short alleles (including $\mathrm{s} / \mathrm{L}_{\mathrm{G}}$ and $\mathrm{L}_{\mathrm{G}} / \mathrm{L}_{\mathrm{G}}$ ) reported more anxiety in the evening when daily-event stress was high compared with individuals with different genotypes, but also less anxiety than other genotypes when experiencing little daily-event stress, a pattern consistent across measurement occasions. Once again the fact that the susceptibility factor did not predict the environmental measure or the outcome is considered important.

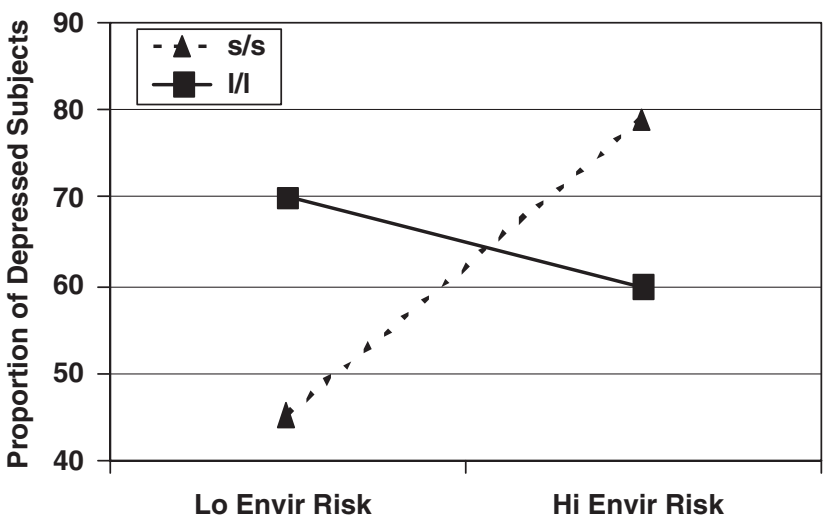

Figure 2 Proportion of female participants with a high level of depression by environmental risk group and 5HTTLPR genotype (Eley et al. ${ }^{28}$ ).
In a second study focused on undergraduate students $(n=247)$ and anxiety, ${ }^{31}$ but this time concerned with (retrospectively reported) emotional abuse in childhood, a $\mathrm{G} \times \mathrm{E}$ interaction once more emerged, with genotype importantly proving unrelated to the environmental predictor and the outcome, anxiety sensitivity. The significantly steeper abuseanxiety slope in the case of students homozygous for short alleles relative to those with one or more long alleles indicated that $\mathrm{s} / \mathrm{s}$ individuals scored highest in anxiety sensitivity when exposed to abuse and lowest when not exposed.

Moving on to consider ADHD (in childhood and adulthood), Retz et al. ${ }^{32}$ focused on the moderated effects of an adverse childhood environment in their study of 184 male delinquents who averaged 34 years of age. Using a retrospective assessment of childhood ADHD as well as of early adversity, but a clinical interview to assess functioning in adulthood, these investigators detected a crossover interaction with respect to the persistence of ADHD over time. Compared with $1 / 1$ genotypes, individuals with 's' alleles had more and less persistent ADHD, depending on whether or not, respectively, they experienced an adverse early environment.

One observation that makes the findings under consideration particularly interesting is that short alleles on the serotonin transporter gene have also been found, in at least some molecular-genetic research, ${ }^{33}$ to be associated with negative emotionality in young infants. What makes this genebehavior linkage particularly important is that, even though negative emotionality or difficult temperament in infants has long been conceptualized as a risk or vulnerability factor for the development of behavior problems in childhood,,$^{34}$ a growing literature on differential susceptibility reveals negatively emotional or difficult infants to be more plastic or malleable than other infants-in a for-better-and-forworse manner. ${ }^{35}$ That is, they do worse than others under poor rearing conditions, but better than others under good ones. Consider in this regard the evidence that infants rated by mothers as highly negatively emotional at 6 months of age not only manifest, relative to other children, more behavior problems in early childhood when experiencing low-quality parenting $^{36}$ or low-quality child care, ${ }^{37,38}$ but also fewer problems and more social skills than other children when exposed to high-quality parenting or child care. Relatedly, Kochanska et al. ${ }^{39}$ observed that highly fearful 15-month-olds experiencing high levels of power-assertive paternal discipline were most likely to cheat in a game at 38 months, yet when cared for in a supportive manner, such negatively emotional, fearful and putatively vulnerable toddlers manifested the most rule-compatible conduct. Even more noteworthy than such longitudinal/correlational evidence is the clinical-trial finding of a parenting intervention designed to promote secure attachment of infant to mother showing that the principle beneficiaries of the documented experimental effect were highly negative 
and fearful infants. ${ }^{40}$ These findings pertaining to negatively emotional infants demonstrate not only that such putatively vulnerable children are more beneficially affected than other infants by some enriching rearing conditions but, in so doing, raise the prospect that this could be because they are carriers of short alleles on the serotonin transporter gene. Only when investigators evaluate interactions involving both the environment and genetics, and the environment and temperament will it be possible to determine whether the same highly plastic individuals are being identified in different studies using different (behavioral and genetic) markers.

\section{DRD4}

Recent research on $\mathrm{G} \times \mathrm{E}$ interaction involving the 7-repeat allele of the dopamine receptor gene, DRD4, which meta-analysis reveals to be reliably associated with ADHD, ${ }^{1}$ also provides support for the claim that the so-called vulnerability genes may be better conceptualized as plasticity genes. What makes the first two studies to be considered especially important is that the predictor variable, parenting, ranges from quite limited to very competent, thus meaning that a supportive environment is not just the one in which adverse experiences are absent. In a longitudinal investigation of 47 infants, greater maternal insensitivity observed when children were 10 months predicted greater externalizing problems reported by the mother more than 2 years later, but only for children carrying the 7-repeat DRD4 allele. ${ }^{41}$ Moreover, although children with the 7-repeat DRD4 allele displayed, consistent with a diathesis-stress model, the most externalizing behavior of all children when mothers were judged insensitive, they also manifested the least externalizing behavior when mothers were highly sensitive (but see, for contradictory results, Propper et $a .^{42}$ ). Similar results emerged in a cross-sectional investigation of sensation seeking involving 45 children who were 18-21-month-olds, with toddlers carrying the 7-repeat allele rated by parents as showing, compared with children without the 7-repeat allele, less sensation seeking behavior when parenting quality was high and more when parenting quality was low. ${ }^{43}$ Although parenting proved significantly associated with sensation seeking in the 7-repeat individuals, it did not in other children. Of importance is the fact that genotype did not predict parenting or sensation seeking, fulfilling important differential-susceptibility criteria.

Experimental intervention research involving the enhancement of parenting also documents a moderating effect of the 7-repeat allele; once again, then, this $\mathrm{G} \times \mathrm{E}$ work does not simply define the 'good' environment in terms of the absence of adversity. Thus, when Bakermans-Kranenburg et al. ${ }^{44}$ looked at the change over time in parenting-from before to well after a video-feedback parenting intervention was provided on a random basis to 157 mothers of 13-year-olds who scored high on externalizing problems-they not only found that the intervention succeeded in promoting more sensitive parenting and positive discipline, but that experimental effects extended to improvements in child behavior. This proved to be the case, however, only for those children carrying the DRD4 7-repeat allele, with most of the experimental effect being carried by these genotypically susceptible children whose mothers showed the most improvement in their parenting. Much the same was the case when, at post-treatment follow up, stress reactivity was measured by means of change in salivary cortisol before and after administration of an experimental stressor (that is, area under the curve ${ }^{44}$ ). Indeed, DRD4 7-repeat children in the experimental group not only showed the least physiological stress reactivity of all children, but the most if their mothers had been assigned to the control group.

The same team of Dutch investigators whose $\mathrm{G} \times \mathrm{E}$ research has focused upon indisputably positive environmental effects also found evidence that the DRD4 7-repeat allele moderated the effect of a maternal psychological condition, unresolved loss or trauma (as measured by means of the Adult Attachment Interview) on early infant development. More specifically, unresolved loss predicted infant attachment disorganization, an early developmental marker of psychological disturbance later in life, ${ }^{45}$ but only in the case of infants carrying the 7 -repeat allele. ${ }^{46}$ Indeed, these infants manifest both the most and least disorganized attachment behavior when stressed depending on whether their mothers had or had not experienced unresolved loss or trauma in their own lives. Importantly, genotype predicted neither unresolved loss nor disorganization, with the data thus meeting criteria for differential susceptibility (rather than just genetic vulnerability).

Finally, in a study with a focus rather different than the ones just considered, Seeger et al. ${ }^{47}$ evaluated whether the season of the year in which a child was born interacted with the dopamine DRD4 polymorphism in predicting the hyperkinetic conduct disorder (ADHD). Employing a cross-sectional design involving 64 children with the disorder and 163 healthy controls (mean age 11-12 \pm 3 years), they found that it did-and in ways consistent with what is known about photoperiod exposure during pregnancy. When comparing patients with controls, children with one copy of the DRD4 7-repeat allele born in autumn and winter (that is, long photoperiod during pregnancy) had a 5.4-fold decreased relative risk for hyperkinetic conduct disorder, whereas children with the same genotype born in spring and summer (that is, short photoperiod) had a 2.8-fold increased relative risk for hyperkinetic conduct disorder. Neither season of birth nor the presence of DRD4 7-repeat allele represented a risk factor for hyperkinetic conduct disorder per se.

\section{Conclusion}

In some respects, it should not be surprising that putative vulnerability genes may actually function 
more like plasticity genes, resulting in certain individuals being more responsive than others to both positive and negative environmental experiences, including the simple absence of contextual adversity. Not only has plasticity been found to be heritable in many species, ${ }^{48,49}$ functioning perhaps as a selectable character in and of itself, ${ }^{50}$ but recent computer simulations show that individual differences in responsiveness to the environment could most certainly evolve. ${ }^{51}$ In fact, one wild bird population shows evidence that selection favoring individuals who are highly plastic with regard to the timing of reproduction has intensified over the past three decades, perhaps in response to climate change causing a mismatch between the breeding times of the birds and their caterpillar prey. ${ }^{52}$ Of note too is Suomi's ${ }^{53}$ observation that only two species of primates fill diverse ecological niches around the world, humans and rhesus macaques, and that what distinguishes both of these 'weed species', as he calls them, from all other primates is the presence of 5HTTLPR short allele in some individuals. It seems unlikely that that which might afford these two species such an adaptive advantage would only be 'vulnerability genes' that predispose carriers to depression in the face of contextual stress.

Given the focus in psychiatric genetics on adversity in the form of environmental risk factors and vulnerability in the form of genes associated with pathological conditions, it is not surprising that the possibility that the so-called vulnerability genes actually function more like plasticity genes could go unnoticed. It is almost as if, metaphorically speaking, sailors are so busy-and wisely-looking under the water line for extensions of icebergs that could sink their ship that they fail to appreciate that by climbing on top of the iceberg it might prove possible to chart a clear passage through the ice-laden sea. To the extent that it is appropriate to think in terms of plasticity rather than vulnerability, research will be required that extends the purview of the molecular-genetic study of behavior well beyond the investigation of dysfunction and environmental adversity. Once again Caspi et al. ${ }^{54}$ have served as groundbreakers, discovering that, with respect to intelligence, children carrying one variant of FADS2, a gene involved in the genetic control of fatty acid pathways, benefit from breastfeeding, whereas those carrying a different allele are not so affected. What has not been determined as of yet, because all mothers in this study were apparently in relatively good nutritional state, is whether those individuals found to benefit from breastfeeding for genetic reasons actually are adversely affected by it when mothers are in poor nutritional condition. Not only is this just what a differential-susceptibility perspective would predict, but is also what might explain why the gene associated with increased intelligence in the context of breastfeeding, most certainly the universal condition in ancestral times, has not gone to fixation.
Although the primary purpose of this essay has been to argue that the virtually exclusive focus on adverse environmental conditions and psychopathology in psychiatric genetic research risks mischaracterizing individuals who are more susceptible than others to the negative consequences of adversity and to the benefits of environmental support and enrichment as being exclusively the former-that is, genetically vulnerable-it would be a mistake to view these orientations as mutually exclusive. Indeed, thinking about plasticity and vulnerability together raises the following three interrelated questions: Are there some polymorphisms that make some individuals more responsive than others to supportive and adverse environments, just as a differential-susceptibility framework presupposes? Are there some polymorphisms that only cause some individuals to be more susceptible than others to adversity, just as a diathesis-stress/genetic-vulnerability framework presupposes? And are there still other polymorphisms that only make individuals more susceptible than others to enriching environmental conditions? Of note, with regard to the last possibility is that, although the English language has terms to characterize those highly susceptible to both positive and negative conditions (that is, plastic/malleable) and highly susceptible to adversity (that is, vulnerable), it is difficult to find a term which would characterize those disproportionately responsive to supportive conditions only-besides lucky!

Owing to the inherent limits of so many of the studies that we have considered, both in terms of what has been measured and how the data have been analyzed and presented in primary publications, it remains impossible to be certain whether the extensive findings considered throughout this paper as evidence of differential susceptibility should be regarded as such. Recall in this regard that rather liberal standards of interpretation have, by necessity, been applied to $\mathrm{G} \times \mathrm{E}$ findings, most of which emerged from investigations designed to evaluate diathesis-stress hypotheses. To enable both primary researchers and reviewers of the literature in the future, including meta-analysts, to address this fundamental issue about how human development operates, investigatory and reporting practices will need to change; and hopefully, this selective review, by calling attention to the possibility of differential susceptibility, will stimulate such change.

Thus, in addition to meeting the Belsky et al. ${ }^{13}$ criteria for establishing differential susceptibility summarized earlier, which informed the interpretation of study findings considered herein, several other research desiderata are called for. First, studies should measure not just the presence of adversity and its absence, but environmental support, like Taylor et $a .^{24}$ did in assessing positive life events and Bakermans-Kranenburg and van IJzendoorn ${ }^{41}$ did in measuring sensitive parenting. Second and relatedly, human functioning should be measured along a continuum ranging from dysfunction to competence, 
not just from dysfunction to its absence or just from competence to its absence, to avoid the masking of differential susceptibility by ceiling or floor effects; should this not prove possible for some reason, separate measurements of negative and positive functioning should be obtained and examined vis-àvis $\mathrm{G} \times \mathrm{E}$. In addition, once a $\mathrm{G} \times \mathrm{E}$ interaction has been discerned, follow-up analysis should determine whether significant differences in the functioning of individuals hypothesized to be more and less susceptible to environmental influences are obtained when the environmental circumstances are adverse as well as when they are supportive (that is, at both ends of the environmental continuum). It is when significant differences are obtained for both comparisons that differential susceptibility rather than diathesis-stress would be the correct inference.

\section{Conflict of interest}

The authors report no biomedical financial interests or potential conflicts of interest.

\section{Acknowledgments}

This research was supported by the National Heart, Lung, and Blood Institutes grant 3P01 HL036587; the National Institute on Aging grant R01AG19605, with co-funding by National Institute of Environmental Health Sciences; the Duke Clinical Research Unit grant M01RR30l; and the Duke Behavioral Medicine Research Center.

\section{References}

1 Burmeister M, McInnis MG, Zollner S. Psychiatric genetics: progress amid controversy. Nat Rev Genet 2008; 9: 527-540.

2 Caspi A, McClay J, Moffitt TE, Mill J, Martin J, Craig IW et al. Role of genotype in the cycle of violence in maltreated children. Science 2002; 297: 851-854.

3 Kim-Cohen J, Caspi A, Taylor A, Williams B, Newcombe R, Craig IW et al. MAOA, maltreatment, and gene-environment interaction predicting children's mental health: new evidence and a metaanalysis. Mol Psychiatry 2006; 11: 903-913.

4 Kagan J. A trio of concerns. Perpsect Psychol Sci 2007; 2: 361-376.

5 Caspi A, Sugden K, Moffitt TE, Taylor A, Craig IW, Harrington H et al. Influence of life stress on depression: moderation by a polymorphism in the 5-HTT gene. Science 2003; 301: 386-389.

6 Zammit S, Owen MJ. Stressful life events, 5-HTT genotype and risk of depression. Br J Psychiatry 2006; 188: 199-201.

7 Rutter M. Genes and Behavior. Blackwell: London, 2006.

8 Moffitt TE. The new look of behavioral genetics in developmental psychopathology: gene-environment interplay in antisocial behaviors. Psychol Bull 2005; 131: 533-554.

9 Rutter M, Moffitt TE, Caspi A. Gene-environment interplay and psychopathology: multiple varieties but real effects. $J$ Child Psychol Psychiatry 2006; 47: 226-261.

10 Boyce WT, Ellis BJ. Biological sensitivity to context: I. An evolutionary-developmental theory of the origins and functions of stress reactivity. Dev Psychopathol 2005; 17: 271-301.

11 Belsky J. Theory testing, effect-size evaluation, and differential susceptibility to rearing influence: the case of mothering and attachment. Child Dev 1997; 68: 598-600.

12 Belsky J. Differential susceptibility to rearing influences: an evolutionary hypothesis and some evidence. In: Ellis B, Bjorklund
D (eds). Origins of the Social Mind: Evolutionary Psychology and Child Development. Guildford: New York, 2005, pp 139-163.

13 Belsky J, Bakermans-Kranenburg MJ, van Ijzendoorn MH. For better and for worse: differential susceptibility to environmental influences. Curr Dir Psychol Sci 2007; 16: 300-304.

14 Belsky J, Pluess M. The nature (and nurture?) of plasticity in early human development. Perspect Psychol Sci 2009; 4: (in press)

15 Dearing E, Hamilton LC. Contemporary advances and classic advice for analyzing mediating and moderating variables. Monogr Soc ResChild Dev 2006; 71: 88-104.

16 Caspi A, Moffitt TE. Gene-environment interactions in psychiatry: joining forces with neuroscience. Nat Rev Neurosci 2006; 7: 583-590.

17 Rutter M. Genes and Behavior: Nature-Nurture Interplay Explained. Blackwell: London, 2006.

18 Foley DL, Eaves LJ, Wormley B, Silberg JL, Maes HH, Kuhn J et al. Childhood adversity, monoamine oxidase a genotype, and risk for conduct disorder. Arch Gen Psychiatry 2004; 61: 738-744.

19 Nilsson KW, Sjoberg RL, Damberg M, Leppert J, Ohrvik J, Alm PO et al. Role of monoamine oxidase A genotype and psychosocial factors in male adolescent criminal activity. Biol Psychiatry 2006; 59: 121-127.

20 Widom CS, Brzustowicz LM. MAOA and the 'cycle of violence' childhood abuse and neglect, MAOA genotype, and risk for violent and antisocial behavior. Biol Psychiatry 2006; 60: 684-689.

21 Frazzetto G, Di Lorenzo G, Carola V, Proietti L, Sokolowska E, Siracusano A et al. Early trauma and increased risk for physical aggression during adulthood: the moderating role of MAOA genotype. PLOS ONE 2007; 2: e486.

22 Ducci F, Enoch MA, Hodgkinson C, Xu K, Catena M, Robin RW et al. Interaction between a functional MAOA locus and childhood sexual abuse predicts alcoholism and antisocial personality disorder in adult women. Mol Psychiatry 2008; 13: 334-347.

23 Surtees PG, Wainwright NW, Willis-Owen SA, Luben R, Day NE, Flint J. Social adversity, the serotonin transporter (5-HTTLPR) polymorphism and major depressive disorder. Biol Psychiatry 2006; 59: 224-229.

24 Taylor SE, Way BM, Welch WT, Hilmert CJ, Lehman BJ, Eisenberger NI. Early family environment, current adversity, the serotonin transporter promoter polymorphism, and depressive symptomatology. Biol Psychiatry 2006; 60: 671-676.

25 Zalsman G, Huang YY, Oquendo MA, Burke AK, Hu XZ, Brent DA et al. Association of a triallelic serotonin transporter gene promoter region (5-HTTLPR) polymorphism with stressful life events and severity of depression. Am J Psychiatry 2006; 163 1588-1593.

26 Lazary J, Lazary A, Gonda X, Benko A, Molnar E, Juhasz G et al. New evidence for the association of the serotonin transporter gene (SLC6A4) haplotypes, threatening life events, and depressive phenotype. Biol Psychiatry 2008; 64: 498-504.

27 Brummett BH, Boyle SH, Siegler IC, Kuhn CM, Ashley-Koch A, Jonassaint CR et al. Effects of environmental stress and gender on associations among symptoms of depression and the serotonin transporter gene linked polymorphic region (5-HTTLPR). Behav Genet 2008; 38: 34-43.

28 Eley TC, Sugden K, Corsico A, Gregory AM, Sham P, McGuffin P et al. Gene-environment interaction analysis of serotonin system markers with adolescent depression. Mol Psychiatry 2004; 9: 908-915.

29 Wilhelm K, Mitchell PB, Niven H, Finch A, Wedgwood L, Scimone A et al. Life events, first depression onset and the serotonin transporter gene. Br J Psychiatry 2006; 188: 210-215.

30 Gunthert KC, Conner TS, Armeli S, Tennen H, Covault J, Kranzler HR. Serotonin transporter gene polymorphism (5-HTTLPR) and anxiety reactivity in daily life: a daily process approach to geneenvironment interaction. Psychosom Med 2007; 69: 762-768.

31 Stein MB, Schork NJ, Gelernter J. Gene-by-environment (serotonin transporter and childhood maltreatment) interaction for anxiety sensitivity, an intermediate phenotype for anxiety disorders. Neuropsychopharmacology 2008; 33: 312-319.

32 Retz W, Freitag CM, Retz-Junginger P, Wenzler D, Schneider M, Kissling $\mathrm{C}$ et al. A functional serotonin transporter promoter gene polymorphism increases ADHD symptoms in delinquents: interaction with adverse childhood environment. Psychiatry Res 2008; 158: $123-131$. 
33 Auerbach JG, Faroy M, Ebstein R, Kahana M, Levine J. The association of the dopamine D4 receptor gene (DRD4) and the serotonin transporter promoter gene (5-HTTLPR) with temperament in 12-month-old infants. J Child Psychol Psychiatry 2001; 42: 777-783.

34 Thomas A, Chess S, Birch HG. Temperament and Behavior Disorders in Children. New York University Press: New York, 1968

35 Belsky J. Differential susceptibility to rearing influences: an evolutionary hypothesis and some evidence. In: Ellis B, Bjorklund D (eds). Origins of the Social Mind: Evolutionary Psychology and Child Development. Guilford: New York, 2005, pp 139-163.

36 Bradley RH, Corwyn RF. Infant temperament, parenting, and externalizing behavior in first grade: a test of the differential susceptibility hypothesis. J Child Psychol Psychiatry 2008; 49: 124-131.

37 Pluess M, Belsky J. Differential susceptibility to parenting and quality child care. Dev Psychol 2009; 50: 386-395.

38 Pluess M, Belsky J. Differential susceptibility to rearing experience: the case of childcare. J Child Psychol Psychiatry 2009; 50: 396-404.

39 Kochanska G, Aksan N, Joy ME. Children's fearfulness as a moderator of parenting in early socialization: two longitudinal studies. Dev Psychol 2007; 43: 222-237.

40 Velderman MK, Bakermans-Kranenburg MJ, Juffer F, van IMH. Effects of attachment-based interventions on maternal sensitivity and infant attachment: differential susceptibility of highly reactive infants. J Fam Psychol 2006; 20: 266-274.

41 Bakermans-Kranenburg MJ, van Ijzendoorn MH. Gene-environment interaction of the dopamine D4 receptor (DRD4) and observed maternal insensitivity predicting externalizing behavior in preschoolers. Dev Psychobiol 2006; 48: 406-409.

42 Propper C, Willoughby M, Halpern CT, Carbone MA, Cox M. Parenting quality, DRD4, and the prediction of externalizing and internalizing behaviors in early childhood. Dev Psychobiol 2007; 49: 619-632.

43 Sheese BE, Voelker PM, Rothbart MK, Posner MI. Parenting quality interacts with genetic variation in dopamine receptor D4 to influence temperament in early childhood. Dev Psychopathol 2007; 19: 1039-1046.

44 Bakermans-Kranenburg MJ, Van IMH, Pijlman FT, Mesman J, Juffer F. Experimental evidence for differential susceptibility: dopamine
D4 receptor polymorphism (DRD4 VNTR) moderates intervention effects on toddlers' externalizing behavior in a randomized controlled trial. Dev Psychol 2008; 44: 293-300.

45 Carlson EA. A prospective longitudinal study of attachment disorganization/disorientation. Child Dev 1998; 69: 1107-1128.

46 Van Ijzendoorn MH, Bakermans-Kranenburg MJ. DRD4 7-repeat polymorphism moderates the association between maternal unresolved loss or trauma and infant disorganization. Attach Hum Dev 2006; 8: 291-307.

47 Seeger G, Schloss P, Schmidt MH, Ruter-Jungfleisch A, Henn FA. Gene-environment interaction of hyperkinetic conduct disorder (HD + CD) as indicated by season of birth variations in dopamine rceptor (DRD4) gene polymorphism. Neurosci Lett 2004; 366: 282-286.

48 Bashey F. Cross-generational environmental effects and the evolution of offspring size in the Trinidadian guppy Poecilia reticulata. Evolution 2006; 60: 348-361.

49 Pigliucci M. Do we need an extended evolutionary synthesis? Evolution 2007; 61: 2743-2749.

50 Sinn DL, Gosling SD, Moltschaniwskyj NA. Development of shy/ bold behaviour in squid: context-specific phenotypes associated with developmental plasticity. Anim Behav 2007; 75: 433-442.

51 Wolf M, van Doorn GS, Weissing FJ. Evolutionary emergence of responsive and unresponsive personalities. Proc Natl Acad Sci USA 2008; 105: 15825-15830.

52 Nussey DH, Postma E, Gienapp P, Visser ME. Selection on heritable phenotypic plasticity in a wild bird population. Science 2005; 310: 304-306.

53 Suomi SJ. Risk, resilience, and gene x environment interactions in rhesus monkeys. Ann N Y Acad Sci 2006; 1094: 52-62.

54 Caspi A, Williams B, Kim-Cohen J, Craig IW, Milne BJ, Poulton R et al. Moderation of breastfeeding effects on the IQ by genetic variation in fatty acid metabolism. Proc Natl Acad Sci USA 2007; 104: 18860-18865.

This work is licensed under the Creative Commons Attribution-NonCommercialNo Derivative Works 3.0 License. To view a copy of this license, visit http://creativecommons.org/ licenses/by-nc-nd/3.0/ 